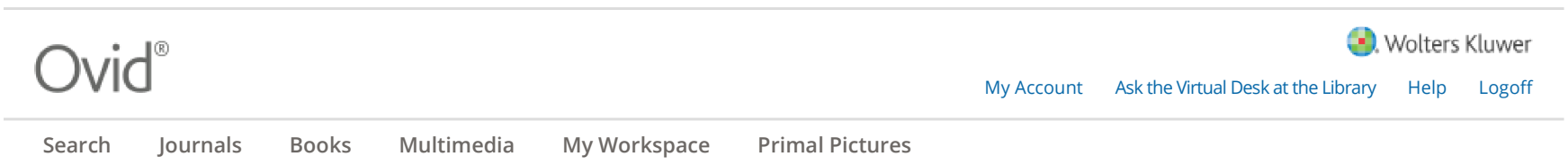

Search Results

\title{
Neurosurgery
}

Issue: Volume 38(1), January 1996, pp 21-31

Copyright: Copyright $\odot$ by the Congress of Neurological Surgeons

Publication Type: [Clinical Studies]

ISSN: 0148-396X

Accession: 00006123-199601000-00007

Keywords: Brain metabolism, Cerebral ischemia, Head injury, Oxygen metabolism

[Clinical Studies] 4 Previous Article | Table of Contents | Next Arti

\section{Severe Head Injury}

van Santbrink, Henk M.D.; Maas, Andrew I.R. M.D., Ph.D.; Avezaat, Cees J.J. M.D., Ph.D.

\section{Author Information}

Department of Neurological Surgery, Academic Hospital Rotterdam, Erasmus University Rotterdam, The Netherlands Received, March 21, 1995. Accepted, July 25, 1995.

Reprint requests: Henk van Santbrink, Department of Neurological Surgery, Academic Hospital Rotterdam, Dr. Molewaterplein 40, 3015 GD Rotterdam, The Netherlands.

\section{Abstract}

ISCHEMIA IS ONE of the major factors causing secondary brain damage after severe head injury. We have investigated the value of continuous partial pressure of brain tissue oxygen $\left(\mathrm{P}_{\mathrm{br}} \mathrm{O}_{2}\right)$ monitoring as a parameter for cerebral oxygenation in 22 patients with severe head injury(Glasgow Coma Scale score, $<=8$ ). Jugular bulb oxygenation, intracranial pressure, and cerebral perfusion pressure were simultaneously recorded. $\mathrm{O}_{2}$ and $\mathrm{CO}_{2}$ reactivity tests were performed daily to evaluate oxygen autoregulatory mechanisms. $\mathrm{Pbr}_{2} \mathrm{O}_{2}$ monitoring was started an average of 7.0 hours after trauma with a mean duration of 74.3 hours. No complications were seen, and the calibration of the catheters after measurement showed a zero drift of $1.2 \pm 0.8 \mathrm{~mm} \mathrm{Hg}$ and a sensitivity drift of $9.7 \pm 5.3 \%$. In $86 \%$ of the patients, $\mathrm{PbrO}_{2}$ was $<20 \mathrm{~mm} \mathrm{Hg}$ in the acute phase. Mean $\mathrm{Pbr}_{\mathrm{br}} \mathrm{O}_{2}$ significantly increased during the first 24 hours after injury. Two distinct patterns of change of $\mathrm{PbrO}_{2}$ over time were noted. The first pattern was characterized by normal stable levels after 24 hours, and the second was characterized by transiently elevated levels of $\mathrm{Pbr}_{\mathrm{br}} \mathrm{O}_{2}$ during the second and third days. $\mathrm{P}_{\mathrm{br}} \mathrm{O}_{2}$ values $<=5 \mathrm{~mm} \mathrm{Hg}$ within 24 hours after trauma negatively correlated with outcome. $\mathrm{O}_{2}$ reactivity was significantly lower in patients with good outcomes. $\mathrm{CO}_{2}$ reactivity showed no constant pattern of change over time and was not correlated with outcome. Increased hyperventilation was shown to decrease $\mathrm{P}_{\mathrm{br}} \mathrm{O}_{2}$ in some patients. Accurate detection of the moment of cerebral death was possible on the basis of the $\mathrm{P}_{\mathrm{br}} \mathrm{O}_{2}$ measurements. The correlation between $\mathrm{P}_{\mathrm{br}} \mathrm{O}_{2}$ and other parameters, such as intracranial pressure and cerebral perfusion pressure, was weak. We conclude that $\mathrm{P}_{\mathrm{br}} \mathrm{O}_{2}$ monitoring is a safe and clinically applicable method in patients with severe head injury. The early occurrence of ischemia after head injury can be monitored on a continuous basis. Deficiency of oxygen autoregulatory mechanisms can be demonstrated, and their occurrence is inversely related to outcome. For practical clinical use, the method seemed to be superior to jugular oximetry.

After severe head injury, various mechanisms lead to secondary brain damage, resulting in increased mortality and morbidity. The final common pathway of these mechanisms is cerebral ischemia. Recent studies have emphasized the importance of maintaining adequate cerebral perfusion pressure(CPP) in patients with head injury $(21,25)$. There is a need for techniques to continuously monitor cerebral oxygenation. Measurements of jugular bulb oxygenation $\left(\mathrm{SjO}_{2}\right)$ are becoming increasingly important. $\mathrm{SjO}_{2}$ levels $<50 \%$, at which ischemia is a potential risk, are considered to be critical $(1,6,24)$. High $\mathrm{SjO}_{2}$ values are supposed to represent hyperemia. However, two major problems exist in continuous $\mathrm{SjO}_{2}$ monitoring with jugular catheters. First, the technique is susceptible to technical artifacts. Low light intensity, movement artifacts, and changes in catheter position are causes of

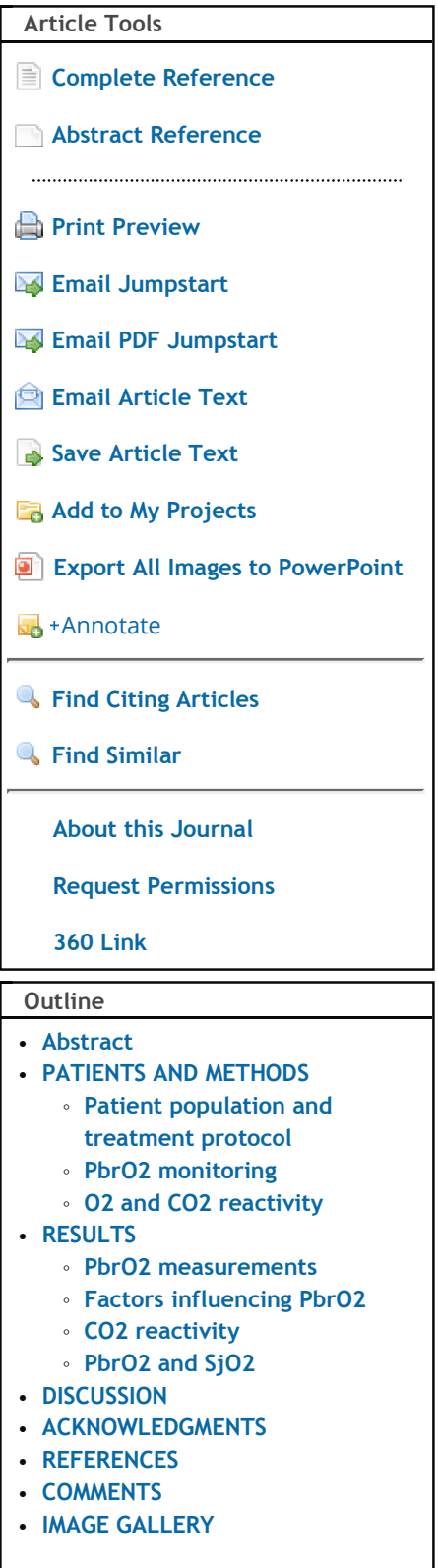


unreliable recordings, sometimes in as much as $50 \%$ of the recording time. Second, even in the presence of normal or high $\mathrm{SjO}_{2}$ values, cerebral oxygenation can be impeded. Vasodilation can result in shunting of blood as a result of short capillaries being ineffective in the transport of oxygen to the brain tissue. Moreover, when flow is absent in one of the segments of the arterial vessels, there is no oxygen transfer in the involved cerebral tissue and, hence, the absolute regional ischemia will not be reflected by changes in oxygen saturation in the venous blood.

In experimental studies, we have shown the feasibility of continuous monitoring of partial pressure of brain tissue oxygen $\left(\mathrm{P}_{\mathrm{br}} \mathrm{O}_{2}\right)$ and further hypothesized on the presence of an oxygen autoregulatory mechanism in the brain $(16,17)$. Preliminary clinical studies showed promising results $(17,29)$. In these studies, $\mathrm{Pbr}_{\mathrm{br}} \mathrm{O}_{2}$ was of predictive value for outcome after severe head injury and seemed to be a measure for global cerebral ischemia. In this article, we report on further clinical experience in monitoring $\mathrm{P}_{\mathrm{br}} \mathrm{O}_{2}$ in patients with severe head injury, as a parameter for cerebral oxygenation. The aim of this study was to verify whether continuous $\mathrm{PbrO}_{2}$ monitoring is applicable in patients with severe head injury and to gain more experience and insight in the value of this new parameter.

Back to Top

\section{PATIENTS AND METHODS}

Back to Top

Patient population and treatment protocol

Twenty-two patients ( 17 male and 5 female) with severe head injury were investigated. The mean age was 26 years (range, 11-52 yr). Informed consent for participation in the study was obtained from the nearest of kin. All patients had Glasgow Coma Scale (GCS) scores of $<=8$ after resuscitation or deteriorated to this level within 8 hours after trauma. The mean GCS score was $6.2 \pm 1.4$. After stabilization, an admission computed tomographic (CT) scan was performed. Mass lesions were evacuated when indicated (seven patients). All patients were admitted to the neurosurgical intensive care unit and treated according to a standard protocol. This included intubation, artificial ventilation, and monitoring of arterial blood pressure (ABP), heart rate, pulse oximetry, intracranial pressure (ICP), CPP $(\mathrm{CPP}=$ mean $\mathrm{ABP}-\mathrm{ICP}), \mathrm{SjO}_{2}$, and end-tidal partial carbon dioxide pressure. These data were stored at 1 -hour intervals. Arterial blood samples were regularly taken for blood gas analysis. The patients were sedated and paralyzed. ICP was intraparenchymally monitored with a fiberoptic device (Camino Laboratories, San Diego, $\mathrm{CA}$ ). $\mathrm{SjO}_{2}$ was monitored with a 4 French flexible near-infrared catheter (Opticath; Abbot Laboratories, North Chicago, IL). The catheter values were recalibrated every 12 hours on the basis of co-oximeter determinations of $\mathrm{SjO}_{2}$. Increased ICP was treated according to a staircase model; when values $>25 \mathrm{~mm} \mathrm{Hg}$ were recorded for at least 5 minutes, patients were moderately hyperventilated to a partial pressure of arterial carbon dioxide $\left(\mathrm{PaCO}_{2}\right)$ of $30.0 \mathrm{~mm} \mathrm{Hg}$. If ICP remained higher than $25 \mathrm{~mm} \mathrm{Hg}$, despite hyperventilation, mannitol infusions were instituted at intervals of 3 to 4 hours. When these measures were insufficient to control ICP, barbiturates were administered (two patients).

Back to Top

$\mathrm{P}_{\mathrm{brO}} \mathrm{O}_{2}$ monitoring

$\mathrm{P}_{\mathrm{br}} \mathrm{O}_{2}$ was monitored with a polarographic microcatheter(Clark-type) with a diameter of $0.5 \mathrm{~mm}$ and a 5-mm-long partial pressure of oxygen $\left(\mathrm{PO}_{2}\right)$-sensitive area connected to a Licox $\mathrm{PO}_{2}$ device(GMS, Kiel, Germany). The response time (T90) at $37^{\circ} \mathrm{C}$ was approximately 80 seconds. $\mathrm{P}_{\mathrm{br}} \mathrm{O}_{2}$ values were stored at 15 -second intervals. For introducing the ICP and $\mathrm{Pbr}_{\mathrm{br}} \mathrm{O}_{2}$ catheters, a special intracranial bolt with three entries was used. In all patients, the intracranial bolt was placed at the right frontal region. Before insertion of the $\mathrm{PO}_{2}$ catheter, catheter-specific calibration values specified by the manufacturer were instituted on the $\mathrm{PO}_{2}$ device. Corrections for variations in central body temperature were made. $\mathrm{P}_{\mathrm{br}} \mathrm{O}_{2}$ recordings lasted for 5 days after trauma or ended when ICP monitoring was no longer indicated. At the end of the observation period, the $\mathrm{PO}_{2}$ microcatheters were calibrated for zero value and sensitivity drift. For zero-value calibration, a sterile fluid that was fully saturated with $\mathrm{N}_{2}$ was used. This fluid has an actual $\mathrm{PO}_{2}$ of zero. The $\mathrm{PO}_{2}$ microcatheter was immersed in this fluid until stable values were obtained. The difference from zero was called the postmeasurement zero drift. Sensitivity drift calibration was performed by suspending the catheter in room air until stable values were obtained. Room air $\mathrm{PO}_{2}$ is approximately $20 \%$ of the actual air pressure. At a room air pressure of $760 \mathrm{~mm} \mathrm{Hg}, \mathrm{PO}_{2}$ should be $154 \mathrm{~mm} \mathrm{Hg}$. The difference between the measured value and the calculated value, given the barometric 


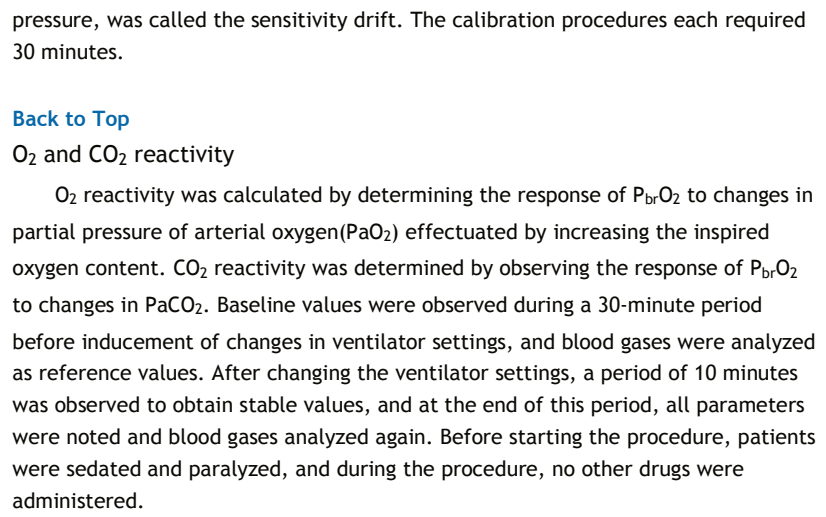

$\mathrm{O}_{2}$ reactivity was calculated by determining the response of $\mathrm{Pbr}_{\mathrm{br}} \mathrm{O}_{2}$ to changes in partial pressure of arterial oxygen $\left(\mathrm{PaO}_{2}\right)$ effectuated by increasing the inspired oxygen content. $\mathrm{CO}_{2}$ reactivity was determined by observing the response of $\mathrm{Pbr}_{2}$ to changes in $\mathrm{PaCO}_{2}$. Baseline values were observed during a 30-minute period before inducement of changes in ventilator settings, and blood gases were analyzed as reference values. After changing the ventilator settings, a period of 10 minutes was observed to obtain stable values, and at the end of this period, all parameters were noted and blood gases analyzed again. Before starting the procedure, patients were sedated and paralyzed, and during the procedure, no other drugs were administered.

For testing $\mathrm{O}_{2}$ reactivity, the fractional inspired oxygen was increased in steps of $20 \%$ until $100 \%$ was reached, inducing an increase of $\mathrm{PaO}_{2} . \mathrm{O}_{2}$ reactivity was calculated as the percentage change in $\mathrm{P}_{\mathrm{br}} \mathrm{O}_{2}$ divided by the actual change in $\mathrm{PaO}_{2}$ :Equation

$\mathrm{P}_{\mathrm{br}} \mathrm{O}_{2(100 \%)}, \mathrm{PaO}_{2(100 \%)}=$ values at a fractional inspired oxygen of $100 \%$.

$\mathrm{P}_{\mathrm{br}} \mathrm{O}_{2 \text { (start) }}, \mathrm{PaO}_{2 \text { (start) }}=$ values at the beginning of the $\mathrm{O}_{2}$ reactivity test (baseline value).

Changes in $\mathrm{PaCO}_{2}$ were induced by increasing the inspiratory minute volume (IMV) by $20 \%$ and subsequently decreasing the IMV to $10 \%$ less than the initial values. If during the changes in IMV, ICP increased to $>25 \mathrm{~mm} \mathrm{Hg}$ when it was initially below this level, the tests were prematurely ended and the ventilator immediately reset (one patient). $\mathrm{CO}_{2}$ reactivity was calculated as the percentage change in $\mathrm{PbrO}_{2}$ divided by the actual change in $\mathrm{PaCO}_{2}$ : Equation

$\mathrm{P}_{\mathrm{br}} \mathrm{O}_{2(20 \%)}, \mathrm{PaCO}_{2(20 \%)}=$ values with an IMV plus $20 \%$ of baseline.

$\mathrm{P}_{\mathrm{br}} \mathrm{O}_{2 \text { (start) }}, \mathrm{PaCO}_{2 \text { (start) }}=$ values at the beginning of the $\mathrm{CO}_{2}$ reactivity test (baseline value).

Back to Top

\section{RESULTS}

Monitoring of $\mathrm{Pbr}_{2} \mathrm{O}_{2}$ started an average of 7.0 hours after trauma (range, 3.5-23 h). The mean duration of monitoring was 74.3 hours(range, 4.0-113.5 h). In 18 patients, monitoring started within 10 hours after trauma; in 4 patients, it started beyond this period. In one patient, this was because of technical problems; in the other three, the initiation of the monitoring was delayed because of emergency operations. In 11 patients, the measurements were terminated before Day 5 after trauma; 5 patients died, ICP levels remained low in 5 patients, not indicating further ICP monitoring, and the $\mathrm{O}_{2}$ catheter broke at Day 4 after trauma in 1 patient. No catheter-related complications were observed; in particular, no infections or catheter-related hematomas were seen.

The $\mathrm{O}_{2}$ microcatheter was calibrated after termination of measurements in 14 patients. Mean zero drift was $1.2 \pm 0.8 \mathrm{~mm} \mathrm{Hg}$ (range, 0.1-3.4 mm Hg), and mean sensitivity drift at open air level was $9.7 \pm 5.3 \%$ (range, $0.6-18.7 \%$ ) at a mean recording time of 86.1 hours(range, 15.4-113.5 h).

Back to Top

$\mathrm{P}_{\mathrm{brO}} \mathrm{O}_{2}$ measurements

In all patients, stable recordings were obtained and no obvious technical artifacts could be seen to influence the measurements. The time course of $\mathrm{Pbr}_{2}$ values averaged over all patients is shown in Figure 1. In 19 of the 22 patients, initially low values of $\mathrm{P}_{\mathrm{br}} \mathrm{O}_{2}\left(\mathrm{P}_{\mathrm{br}} \mathrm{O}_{2},<=20 \mathrm{~mm} \mathrm{Hg}\right)$ were observed. A significant

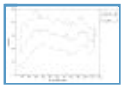

Figure 1

increase in mean $\mathrm{PbrO}_{2}$ values during the first 24 hours after trauma was observed $(P$ $=0.002$; Wilcoxon test), increasing from $16.6 \pm 9.1 \mathrm{~mm} \mathrm{Hg}$ to relatively high levels of $35.8 \pm 14.7 \mathrm{~mm} \mathrm{Hg}$. During the second day after trauma, a decline of the mean $\mathrm{Pbr}_{\mathrm{br}} \mathrm{O}_{2}$ to mean values of $25.1 \pm 12.2 \mathrm{~mm} \mathrm{Hg}$ was noted. 
Because, theoretically, the observed time course of mean $\mathrm{Pbr}_{\mathrm{br}} \mathrm{O}_{2}$ could be influenced by the changing numbers of patients, because some died early or recovered, the same analysis was performed for patients monitored over 96 hours. Also, in this analysis, the same pattern of changes in mean $\mathrm{PbrO}_{2}$ over time was noted.

In individual patients two distinct patterns of changes in $\mathrm{P}_{\mathrm{br}} \mathrm{O}_{2}$ over time were seen:

1. Initially low values increased to levels of approximately $30 \mathrm{~mm} \mathrm{Hg}$ on average within 24 hours after injury (range, 20-36 h) and then stabilized at this level. This pattern was seen in 10 patients (Fig. 2A).

2. Initially low values increased to levels higher than normal from 12 to 48 hours after trauma and returned to normal or slightly elevated levels within 36 to 72 hours. This pattern of response, characterized by temporarily elevated levels of $\mathrm{PbrO}_{2}$, was seen in nine patients (Fig. 2B).

The other three patients did not fit into one of these two patterns; two patients died early, and one patient showed stable values from the onset of measurements.

In four patients, wave forms could be observed in the $\mathrm{P}_{\mathrm{br}} \mathrm{O}_{2}$ recordings. These wave forms did not show a consistent pattern and differed among patients in frequency, amplitude, and duration. Wave forms were present only during relatively short periods of the recording time, varying between 12 and 32 hours with an amplitude of 7 to $25 \mathrm{~mm} \mathrm{Hg}$. An example of waves occurring on the $\mathrm{Pbr}_{2}$ recordings is shown in Figure 3. There was no relationship between the observed waves and either CPP, ICP, or $\mathrm{SjO}_{2}$.

Six of the 22 patients had $\mathrm{Pbr}_{\mathrm{br}} \mathrm{O}_{2}$ values of $<=5 \mathrm{~mm} \mathrm{Hg}$. The mean duration per patient for these low values was 4.3 hours $(0.5-7.1 \mathrm{~h})$. In five of these six patients, low values were measured within the first 24 hours after trauma. The early low $\mathrm{P}_{\mathrm{br}} \mathrm{O}_{2}$ values of $<=5 \mathrm{~mm} \mathrm{Hg}$ negatively correlated with outcome 6 months after trauma (Table 1). Four of the five patients with very low $\mathrm{Pbr}_{2}$ values within 24 hours after trauma died. In contrast, only 1 of the 16 patients without low $\mathrm{Pbr}_{2}$ values within 24 hours after trauma died. The difference in outcome between the patients with and without $\mathrm{P}_{\mathrm{br}} \mathrm{O}_{2}$ values of $<=5 \mathrm{~mm} \mathrm{Hg}$ was significant at a level of $P$ $<0.04$ (Fisher's exact test). In one patient with low $\mathrm{P}_{\mathrm{br}} \mathrm{O}_{2}$ values within 24 hours after trauma who survived, the $\mathrm{CT}$ scan showed a right frontal contusion.

$\mathrm{PbrO}_{2}$ values of $<=5 \mathrm{~mm} \mathrm{Hg}$ within 24 hours after trauma were not correlated to the postresuscitation GCS score, age, sex, or presence of hypoxia before resuscitation (Table 2). $\mathrm{P}_{\mathrm{br}} \mathrm{O}_{2}$ values of $<=5 \mathrm{~mm} \mathrm{Hg}$ after the initial post-traumatic period occurred in three patients. In two patients, this happened at the moment of cerebral herniation and brain death. This is demonstrated in Figure 4. In the other patient, several relatively short periods of low $\mathrm{P}_{\mathrm{br}} \mathrm{O}_{2}$ values were seen immediately after tracheal suctioning procedures when the ICP increased and the CPP temporarily decreased. In this patient, there also was a cerebral contusion in the right frontal lobe. The low values in this patient probably are indicative of regional ischemia and not of global ischemia.

Back to Top

Factors influencing $\mathrm{P}_{\mathrm{br}} \mathrm{O}_{2}$

The records of individual patients were scrutinized to detect factors influencing $\mathrm{P}_{\mathrm{br}} \mathrm{O}_{2}$. The major influence was exerted by changes in $\mathrm{PaO}_{2}$ and lesser influences by changes in $\mathrm{PaCO}_{2}$ and the extent of sedation and paralysis.

The effects of $\mathrm{PaO}_{2}$ on $\mathrm{PbrO}_{2}$ were noted most during preoxygenation before tracheal suctioning procedures. However, the response in individual patients was variable; in general, patients showed a large increase in $\mathrm{P}_{\mathrm{br}} \mathrm{O}_{2}$ (Fig. 5). In some patients, the depth of sedation and paralysis seemed to influence $\mathrm{P}_{\mathrm{br}} \mathrm{O}_{2}$, lower values being noted at deeper sedation No effect of mannitol infusions could be seen on $\mathrm{P}_{\mathrm{br}} \mathrm{O}_{2}$.

To analyze the relationship between $\mathrm{P}_{b r} \mathrm{O}_{2}$ and mean $A B P$, ICP, and CPP, the 1 -hour values were analyzed. Although in individual patients some effects of changes in mean $A B P, I C P$, or $C P P$ could be seen on $\mathrm{Pbr}_{2}$, this response was 
variable and, over the total population, the correlation was absent, as demonstrated by low correlation coefficients of 0.096 to 0.19 for these parameters.

$\mathrm{O}_{2}$ reactivity tests were performed in 18 of 22 patients studied. A linear relationship between $\mathrm{P}_{\mathrm{br}} \mathrm{O}_{2}$ and $\mathrm{PaO}_{2}$ over the ranges measured was found with a mean correlation coefficient in individual patients of $0.93 \pm 0.13$. Differences in $\mathrm{O}_{2}$ reactivity were found during the period of observation within a patient and among patients (Fig. 6). For the total period of observation, a significant difference in mean $\mathrm{O}_{2}$ reactivity was found between patients with favorable and unfavorable outcomes ( $P=0.0003$; Mann-Whitney test). Patients with good outcomes had lower $\mathrm{O}_{2}$ reactivity than did patients with poor outcomes. When the data were analyzed per day, a significant difference in $\mathrm{O}_{2}$ reactivity could also be found between these two groups on Day 1 ( $P=0.02$; Mann-Whitney test). During the subsequent days, no statistical difference was seen.

For the total group of patients, mean $\mathrm{O}_{2}$ reactivity on Day 1 was $0.54 \pm 0.41$ $\mathrm{mm} \mathrm{Hg}{ }^{-1}$. Compared with the other days of observation, this was the lowest mean value, but differences did not reach statistical significance. In the patients with favorable outcomes, mean $\mathrm{O}_{2}$ reactivity showed a significant increase during the period of observation ( $P=0.02$; Student's $t$ test). In patients with unfavorable outcomes, $\mathrm{O}_{2}$ reactivity constantly remained high (Table 3 ).

The $\mathrm{O}_{2}$ reactivity was separately analyzed between the two groups of patients, demonstrating the different patterns of $\mathrm{Pbr}_{\mathrm{br}} \mathrm{O}_{2}$ change over time, as described. In the second group, characterized by temporary elevation of $\mathrm{Pbr}_{\mathrm{br}}$, the mean $\mathrm{O}_{2}$ reactivity was significantly higher $(P=0.02$; Mann-Whitney test). No correlation could be demonstrated between $\mathrm{O}_{2}$ reactivity and postresuscitation GCS, ICP, or CPP.

Back to Top

$\mathrm{CO}_{2}$ reactivity

Eighteen patients underwent $\mathrm{CO}_{2}$ reactivity tests. In one patient, studies on Day 4 were prematurely ended because the ICP increased to $>25 \mathrm{~mm} \mathrm{Hg}$ at a slight increase in $\mathrm{PaCO}_{2}$.

The correlation between $\mathrm{PbrO}_{2}$ and $\mathrm{PaCO}_{2}$ in all patients was weak and varied among patients and in patients during periods of observations. A mean correlation coefficient of $0.32 \pm 0.26$ was found. To compute $\mathrm{CO}_{2}$ reactivity, baseline values and values after increasing the IMV by $20 \%$ were used. The induced changes in $\mathrm{PaCO}_{2}$, however, were small, varying between $3.8 \mathrm{~mm} \mathrm{Hg}$ on Day 1 and $2.3 \mathrm{~mm} \mathrm{Hg}$ on Days 2 and 3. On all days, a decrease in mean $\mathrm{P}_{\mathrm{brO}} \mathrm{O}_{2}$ was found after a period of hyperventilation, which was most prominent on Day 5 after injury (Fig. 7).

The mean $\mathrm{CO}_{2}$ reactivity on Day 1 was significantly lower than that on Days 3 ( $P$ $<0.04)$ and $5\left(P<0.02\right.$; Student'st test) (Table 4). In contrast to the data on $\mathrm{O}_{2}$ reactivity, no relationship existed between $\mathrm{CO}_{2}$ reactivity and outcome. Nor was there any relationship between $\mathrm{CO}_{2}$ reactivity and postresuscitation $\mathrm{GCS}$, ICP, or CPP.

Back to Top

\section{$\mathrm{P}_{\mathrm{brO}}$ and $\mathrm{SjO}_{2}$}

Jugular bulb oximetry was performed in 17 of 22 patients and started an average of 7.5 hours (range, $2.5-12 \mathrm{~h}$ ) after trauma. The mean recording time was 97.0 hours (range, 15.8-144). Every 12 hours, the catheter was calibrated in vivo. In $13.6 \pm 12.7 \%$ of the total recording time, and in $17.7 \pm 17.6 \%$ during the first 24 hours after trauma, the obtained values were unreliable because of technical problems. In 16 patients, 95 calibrations were performed. The mean precalibration values were $67 \pm 14 \%$, and the mean postcalibration values were $66 \pm 10 \%$. These values did not significantly differ. In $81 \%$ of the calibrations, the $\mathrm{SjO}_{2}$ value had to be readjusted, with a range of -29 to $31 \%$, and in $25 \%$ of all calibrations, readjustment of the $\mathrm{SjO}_{2}$ value was $>10 \%$.

The mean $\mathrm{SjO}_{2}$ time course showed a pattern similar to the mean $\mathrm{Pbr}_{\mathrm{br}} \mathrm{O}_{2}$ time course. During the first 24 hours after trauma, the mean $\mathrm{SjO}_{2}$ values were approximately $65 \%$ and increased until mean values were nearly $80 \% 60$ hours after trauma (Fig. 8).

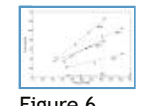

Figure 6

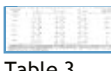

Table 3

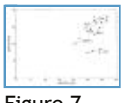

Figure 7

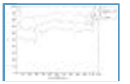

Figure 8 
Mean correlation between $\mathrm{Pbr}_{2} \mathrm{O}_{2}$ and $\mathrm{SjO}_{2}$ was $0.35 \pm 0.25$ (range, -0.13 to 0.72 ). In only two patients was a correlation of $>0.7$ found. Low $\mathrm{P}_{\mathrm{br}} \mathrm{O}_{2}$ levels were not always accompanied by low $\mathrm{SjO}_{2}$ levels; on the contrary, in some patients, high $\mathrm{SjO}_{2}$ values were seen when $\mathrm{PbrO}_{2}$ was low (Fig. 9, $\mathrm{A}$ and $\mathrm{B}$ ).

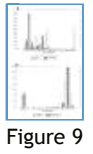

Back to Top

\section{DISCUSSION}

In this study, $\mathrm{PbrO}_{2}$ measurements have proven to be a clinically applicable, easy-to-handle, and reliable monitoring technique. Only once were measurements prematurely ended because the catheter connection to the intracranial bolt broke. No infections at the catheter site were seen. During several days of measurements, the $\mathrm{Pbr}_{\mathrm{br}} \mathrm{O}_{2}$ microcatheters proved to be accurate and did not show serious drift, so there was no need for comprehensive calibration procedures. Preinsertion calibration is possible with calibration of the catheter in an $\mathrm{O}_{2}$-free nitrogen solution and subsequently in room air. This procedure, however, takes approximately 1 hour and has the potential risk of compromising sterility. Therefore, we chose to use the manufacturer's catheter-specific calibration settings. The postmeasurement recalibration results have validated this approach. We think that the technique of $\mathrm{P}_{\mathrm{br}} \mathrm{O}_{2}$ monitoring is superior to continuous jugular bulb oximetry regarding the stability of the recordings. In jugular bulb oximetry, in vivo calibrations are required every 12 hours. Sheinberg et al. (27) have demonstrated a very good correlation between $\mathrm{SjO}_{2}$ values obtained by catheter and those obtained by direct measurement of $\mathrm{O}_{2}$ saturation by a co-oximeter. In our studies, we also found an excellent correlation between pre- and postcalibration values of $\mathrm{SjO}_{2}$ but readjustments of $>10 \%$ were made in $25 \%$ of the calibrations performed. The number and degree of readjustments performed in the jugular oximetry calibrations are undesirable in a monitoring technique for routine clinical use.

Few data exist on normal values of $\mathrm{PbrO}_{2}$ in humans. In the experimental situation, we found normal values of $\mathrm{Pbr}_{2}$ of 25 to $30 \mathrm{~mm} \mathrm{Hg}$ at a $\mathrm{PaO}_{2}$ of 102 to $104 \mathrm{~mm} \mathrm{Hg}$ in dogs (17). These values agree with the measurements obtained in patients under stable conditions. Values of 33 to $36 \mathrm{~mm} \mathrm{Hg}$ have been reported by Assad et al. (2) in three patients at a $\mathrm{PaO}_{2}$ of 150 to $170 \mathrm{~mm} \mathrm{Hg}$. These values, however, were measured during brain tumor surgery, and therefore, whether these can be considered representative of a normal situation is debatable. Higher values of $\mathrm{P}_{\mathrm{brO}} \mathrm{O}_{2}$ have been reported by Kayama et al.(13) and Meixensberger et al. (20). Their measurements, however, were performed with surface electrodes, and in the study by Kayama et al., the measurements were performed in peritumoral edematous tissue. It is conceivable that with surface electrodes, the presence of outside air can influence the measurements, causing falsely high levels of $\mathrm{P}_{\mathrm{br}} \mathrm{O}_{2}$ values. Alternatively, it is conceivable that in surface measurements, the $\mathrm{PO}_{2}$ in subarachnoid cerebral spinal fluid (CSF) is measured. In the experimental situation, we found $\mathrm{PO}_{2}$ levels of 41 to $47 \mathrm{~mm} \mathrm{Hg}$ in the subarachnoid CSF (17).

We have no explanation for the occurrence of wave forms as observed in four patients. In the patient demonstrated in Figure 3, the $\mathrm{Pbr}_{2} \mathrm{O}_{2}$ levels at the top of the waves reach levels known to exist in subarachnoid CSF. Control CT scan studies in this patient demonstrated the catheter to lie deeply in the frontal lobe approaching the midline. Whether the waves demonstrated in this patient result from intermittent contact with the subarachnoid CSF or represent a true physiological phenomenon remains unresolved.

The observed results of the $\mathrm{Pbr}_{\mathrm{br}} \mathrm{O}_{2}$ measurements should be critically appraised, as should those of any new monitoring technique. In the majority of patients studied, initially low $\mathrm{Pbr}_{\mathrm{br}} \mathrm{O}_{2}$ values were observed. The question can be raised of whether these low levels are real or the result of catheter-related artifacts. Directly after positioning the $\mathrm{PO}_{2}$ electrode, generally high values were seen decreasing to the described low levels within 10 to 20 minutes. This can obviously be considered to be an artifact caused by manipulation of the catheter on introduction and a subsequent temperature equilibration. A period of at least 30 to 45 minutes of equilibration is required before obtaining valid data. Hence, the data analysis in this study was performed only on recordings after this period. The slow increase over many hours in $\mathrm{P}_{\mathrm{br}} \mathrm{O}_{2}$ observed in the majority of patients did not have the characteristics of an artifact, and such a response was not seen in the animal experiments performed earlier, either (16). It is, therefore, our considered opinion that the initially low $\mathrm{Pbr}_{\mathrm{br}} \mathrm{O}_{2}$ values seen in patients for periods of up to 24 hours after trauma represent a real physiological phenomenon and are indicative of cerebral ischemia in this early post-traumatic phase. This opinion is consistent with the 
results of several experimental studies investigating metabolic products with magnetic resonance imaging spectroscopy of a failing energy metabolism after head injury. Parallel to the severity of the induced trauma, the adenosine triphosphate content of the brain decreases and the content of inorganic phosphate increases, consistent with the presence of cerebral ischemia $(10,15,28)$.

Ischemic periods after head injury are common (8), and their occurrence and duration are negatively correlated with outcome. Accurate detection of these ischemic insults is difficult with the currently available monitoring systems or requires comprehensive investigational methods ( $5,8,18,26,27)$. During transcranial Doppler studies, we demonstrated "low flow velocity states" in $43 \%$ of the patients during the first 36 hours after trauma (30). Forty percent of the patients with low flow velocities died. Bouma et al. $(3,4)$ showed with xenon CT scanning in the very early phase after trauma that there is an ischemic episode in as many as $33 \%$ of the patients with severe head injury. In the studies presently described, 5 of the 22 patients $(23 \%)$ had $\mathrm{P}_{\mathrm{br}} \mathrm{O}_{2}$ values of $<5 \mathrm{~mm} \mathrm{Hg}$ within 24 hours after trauma. Low $\mathrm{P}_{\mathrm{br}} \mathrm{O}_{2}$ values within 24 hours after trauma suggest, therefore, a cerebral blood flow (CBF) of less than ischemic levels. Jaggi et al.(11) have demonstrated significantly depressed cerebral metabolic rate of $\mathrm{O}_{2}$ levels in patients with severe head injury who died or remained vegetative. In our studies, we found very low levels of $\mathrm{PbrO}_{2},<=5 \mathrm{~mm} \mathrm{Hg}$, in the initial phase after trauma to indicate a poor prognosis. Four of five patients with such low levels died. In the one surviving patient with a $\mathrm{P}_{\mathrm{br}} \mathrm{O}_{2}$ of $<=5 \mathrm{~mm} \mathrm{Hg}$, a cerebral contusion was present in the right frontal lobe, probably indicating local ischemia. It must be realized that a disadvantage of the technique used is that only very regional $\mathrm{PO}_{2}$ is measured. Changes of $\mathrm{P}_{\mathrm{br}} \mathrm{O}_{2}$ may occur in other regions of the brain not monitored. The catheter should preferably be placed in a relatively undamaged part of the cerebral tissue, and the results measured can then be considered indicative of global cerebral oxygenation. Given this presumption, it can be inferred from our studies that $\mathrm{P}_{\mathrm{br}} \mathrm{O}_{2}$ levels of $<=5 \mathrm{~mm} \mathrm{Hg}$ are absolutely critical. In older studies, Jöbsis (12) calculated an upper limit $\mathrm{PO}_{2}$ level of $5 \mathrm{~mm} \mathrm{Hg}$ as critical for ascites tumor cells and liver cells, and Davies and Bronk (7) calculated that the cerebral cortex should function normally until the limiting level of $<5 \mathrm{~mm} \mathrm{Hg} \mathrm{PO}$ is reached. We would, however, not advocate a $\mathrm{PbrO}_{2}$ level of $5 \mathrm{~mm} \mathrm{Hg}$ as a minimal requirement in patients with severe brain injury. The $\mathrm{P}_{\mathrm{br}} \mathrm{O}_{2}$ levels in these patients, prone to secondary brain damage, should preferably be maintained at higher levels, probably between 10 and $15 \mathrm{~mm} \mathrm{Hg}$. The level of $\mathrm{Pbr}_{2}$ below which ischemia can be considered a hazard in these patients, however, has yet to be more accurately determined.

$A \mathrm{PbrO}_{2}$ of $<=5 \mathrm{~mm} \mathrm{Hg}$ beyond the initial 24 hours after trauma occurred in only three patients. In two of these patients, this occurred during the development of brain death and the cessation of cerebral circulation. It is remarkable as demonstrated in Figure 4 that at the moment of herniation and subsequent brain death, a sharp decrease of $\mathrm{P}_{\mathrm{br}} \mathrm{O}_{2}$ to levels just higher than zero is seen, without being preceded by intermittent low levels or a gradual decline in $\mathrm{Pbr}_{\mathrm{br}} \mathrm{O}_{2}$. As also shown in Figure 4, $\mathrm{SjO}_{2}$ increases at the cessation of circulation. We think that the actual moment of occurrence of brain death can be accurately determined on the basis of the $\mathrm{Pbr}_{2} \mathrm{O}_{2}$ measurements. The diagnosis of brain death itself, however, cannot be made on the basis of the $\mathrm{Pbr}_{\mathrm{b}} \mathrm{O}_{2}$ measurements alone because of the regional character of the measurements. However, given the clinical diagnosis of brain death, the moment at which cessation of cerebral circulation occurs can be determined and further investigations, legally required before transplant procedures, can then be instituted without delay. On the basis of $\mathrm{SjO}_{2}$ levels, the moment that brain death occurs cannot be accurately determined because high $\mathrm{SjO}_{2}$ levels can also be caused by luxury perfusion or shunting. Besides, when cerebral circulation ceases, blood flow in the jugular vein will be diminished and, consequently, $\mathrm{SjO}_{2}$ values can become inaccurate because of low light intensity levels. In the one patient in whom short episodes of low $\mathrm{P}_{\mathrm{br}} \mathrm{O}_{2}$ values were observed more than 24 hours after trauma, there was also a right frontal lobe contusion. Again, in this patient, the low levels could be considered indicative of local ischemia.

$\mathrm{PbrO}_{2}$ is thought to reflect the balance between oxygen offer and demand. Oxygen offer is determined by arterial oxygen content and CBF; the demand is determined by cerebral metabolism, inclusive of mitochondrial function. Decreased $\mathrm{P}_{\mathrm{br}} \mathrm{O}_{2}$ can theoretically be caused by inadequate oxygen offer (i.e., low $C B F$ ) or increased metabolism. Increased $\mathrm{P}_{\mathrm{br}} \mathrm{O}_{2}$ levels can result from uncoupling between $\mathrm{CBF}$ and metabolism or failure of oxygen autoregulatory mechanisms. Based on the results of our experimental studies, we found evidence for the presence of an 
oxygen autoregulatory mechanism. Recently, Meixensberger et al.(20) also found evidence in clinical studies for such an oxygen autoregulatory response, although several authors in earlier years hypothesized on the existence of an oxygen autoregulatory mechanism (23).

Evaluating the time course of $\mathrm{P}_{\mathrm{br}} \mathrm{O}_{2}$ changes after trauma, we noted two patterns of response. In the first group, $\mathrm{P}_{\mathrm{br}} \mathrm{O}_{2}$ increases after initially being low to stable levels between 24 and 48 hours after trauma. In the second group, a period of elevated levels was found after 36 to 72 hours. Indeed, in this second group, a significantly higher $\mathrm{O}_{2}$ reactivity was demonstrated, which we consider to be indicative of a distrubed autoregulatory response. High $\mathrm{O}_{2}$ reactivity during the acute phase after trauma was also shown to correlate with a poor outcome. Disturbed $\mathrm{O}_{2}$ regulatory mechanisms would therefore imply more serious damage to the brain. In patients with good outcomes, these mechanisms seem to be relatively spared in the initial phase. However, during subsequent days, an increase in $\mathrm{O}_{2}$ reactivity is seen in all patients. During the last day of the studies (Day 5), $\mathrm{O}_{2}$ reactivity in patients with good outcomes tended to decrease. Therefore, it can be inferred that disturbances in $\mathrm{O}_{2}$ regulatory mechanisms are most pronounced during Days 2 to 4.

$\mathrm{Pbr}_{2}-\mathrm{CO}_{2}$ reactivity did not show a constant pattern during the period of observation and was not related to outcome. The response in individual patients was variable. Theoretically, $\mathrm{P}_{\mathrm{br}} \mathrm{O}_{2}$ was expected to decrease when $\mathrm{PaCO}_{2}$ decreased, as vasoconstriction is known to reduce $\mathrm{CBF}$. Such a response was indeed demonstrated in some patients, as illustrated in Figure 7. However, the relationship was not this clear in every patient. A clear relationship between $\mathrm{PaCO}_{2}$ and $\mathrm{CBF}$ and transcranial Doppler ultrasound recordings has been shown (14, 19, 22). Possibly, the changes in $\mathrm{PaCO}_{2}$ effected during our studies were, in some patients, too small to elicit obvious responses. The variable response in $\mathrm{CO}_{2}$ reactivity observed between patients can, however, be interpreted in a different way, namely, that on the basis of the $\mathrm{CO}_{2}$ reactivity, the ability of the patients to tolerate more intensive hyperventilation therapy can be analyzed.

At the onset of the studies, we had hoped to find a clear correlation between the results of $\mathrm{Pbr}_{\mathrm{br}}$ measurements and the results of jugular oximetry. Although a very good correlation existed in some patients, this was certainly not the case in all patients. In some patients in the early post-traumatic phase, we observed low levels of $\mathrm{P}_{\mathrm{br}} \mathrm{O}_{2}$ when jugular oxygen saturation was high. Based on the jugular saturation, these patients would be considered hyperemic. These patients may have been hyperemic, but the blood was then probably shunted and ineffective in oxygen transport, resulting in ischemia at the tissue level. $\mathrm{High} \mathrm{SjO}_{2}$ values were also seen in patients with brain death, because of an absence of oxygen extraction by the cerebral tissue. Also, $\mathrm{P}_{\mathrm{br}} \mathrm{O}_{2}$ was very low in these patients, near zero. We think, therefore, that a high jugular oxygen saturation does not preclude the presence of cerebral ischemia.

In our studies, we found no clear correlation between $\mathrm{Pbr}_{\mathrm{br}} \mathrm{O}_{2}$ and ICP or CPP. It may, therefore, be concluded that measurements of $\mathrm{P}_{\mathrm{br}} \mathrm{O}_{2}$ in patients with severe head injury afford other valuable information and should be advocated in conjunction with ICP and CPP monitoring in these patients. The method is easily applicable in the clinical situation and, in our experience, is superior to jugular oximetry, regarding technical artifacts influencing the measurements. In our experience, better insight in cerebral oxygenation is obtained with $\mathrm{Pbr}_{2}$ measurements. Further research is necessary to analyze whether therapy aimed at increasing $\mathrm{P}_{\mathrm{br}} \mathrm{O}_{2}$ will yield better treatment results.

Back to Top

\section{ACKNOWLEDGMENTS}

We express gratitude to Dr. A. Marmarou for valuable suggestions and comments during the studies, to Dr. C. Robertson for reviewing the manuscript, to Dr. W. Fleckenstein for support during the studies, and to Nanda Elink Schuurman for typing the manuscript.

Back to Top

\section{REFERENCES}

1. Andrews PJD, Dearden NM, Miller JD: Jugular bulb cannulation: Description of a cannulation technique and validation of a new continuous monitor. $\mathrm{Br} \mathrm{J}$ Anaesth 67:553-558, 1991. 360 Link| Bibliographic Links| [Context Link] 


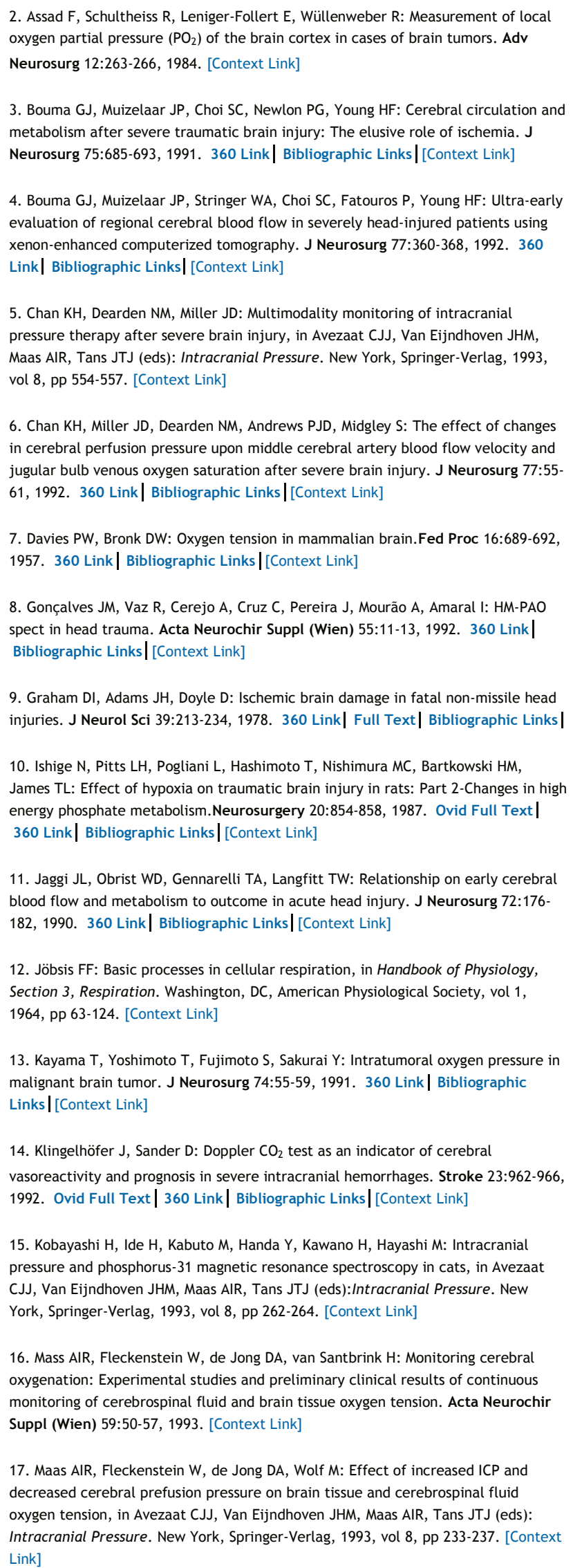

7. Davies PW, Bronk DW: Oxygen tension in mammalian brain.Fed Proc 16:689-692, 1957. 360 Link| Bibliographic Links|[Context Link]

8. Gonçalves JM, Vaz R, Cerejo A, Cruz C, Pereira J, Mourão A, Amaral I: HM-PAO spect in head trauma. Acta Neurochir Suppl (Wien) 55:11-13, 1992. 360 Link|

11. Jaggi JL, Obrist WD, Gennarelli TA, Langfitt TW: Relationship on early cerebral blood flow and metabolism to outcome in acute head injury. J Neurosurg 72:176182, 1990. 360 Link| Bibliographic Links|[Context Link]

12. Jöbsis FF: Basic processes in cellular respiration, in Handbook of Physiology, Section 3, Respiration. Washington, DC, American Physiological Society, vol 1, 1964, pp 63-124. [Context Link]

13. Kayama $T$, Yoshimoto $T$, Fujimoto $S$, Sakurai $Y$ : Intratumoral oxygen pressure in malignant brain tumor. J Neurosurg 74:55-59, 1991. 360 Link| Bibliographic Links | [Context Link]

14. Klingelhöfer J, Sander D: Doppler $\mathrm{CO}_{2}$ test as an indicator of cerebral vasoreactivity and prognosis in severe intracranial hemorrhages. Stroke 23:962-966, 1992. Ovid Full Text | 360 Link| Bibliographic Links|[Context Link]

15. Kobayashi $\mathrm{H}$, Ide $\mathrm{H}$, Kabuto $\mathrm{M}$, Handa $\mathrm{Y}$, Kawano $\mathrm{H}$, Hayashi M: Intracranial pressure and phosphorus-31 magnetic resonance spectroscopy in cats, in Avezaat CJJ, Van Eijndhoven JHM, Maas AIR, Tans JTJ (eds):Intracranial Pressure. New York, Springer-Verlag, 1993, vol 8, pp 262-264. [Context Link]

16. Mass AIR, Fleckenstein W, de Jong DA, van Santbrink H: Monitoring cerebral oxygenation: Experimental studies and preliminary clinical results of continuous monitoring of cerebrospinal fluid and brain tissue oxygen tension. Acta Neurochir Suppl (Wien) 59:50-57, 1993. [Context Link]

17. Maas AIR, Fleckenstein W, de Jong DA, Wolf M: Effect of increased ICP and decreased cerebral prefusion pressure on brain tissue and cerebrospinal fluid oxygen tension, in Avezaat CJJ, Van Eijndhoven JHM, Maas AIR, Tans JTJ (eds): Intracranial Pressure. New York, Springer-Verlag, 1993, vol 8, pp 233-237. [Context Link] 
18. Marion DW, Darby J, Yonas H: Acute regional cerebral blood flow changes
caused by severe head injuries. J Neurosurg 74:407-414, 1991. 360 Link | Bibliographic Links | [Context Link]

19. Markwalder TM, Grolimund P, Seiler RW, Roth F, Aaslid R: Dependency of blood flow velocity in the middle cerebral artery and end-tidal carbon dioxide partial pressure: A transcranial ultrasound Doppler study.J Cereb Blood Flow Metab 4:368372, 1984. 360 Link| Bibliographic Links|[Context Link]

20. Meixensberger J, Dings J, Kuhnigk $\mathrm{H}$, Roosen K: Studies of tissue $\mathrm{PO}_{2}$ in normal and pathological human brain cortex.Acta Neurochir Suppl (Wien) 59:58-63, 1993. 360 Link| Bibliographic Links| [Context Link]

21. Mendelow AD, Allcutt DA, Chambers I, Jenkins A, Crawford PJ, Sultan H: Intracranial and cerebral perfusion pressure monitoring in the head injured patient: Which index? in Avezaat CJJ, Van Eijndhoven JHM, Maas AIR, Tans JTJ (eds): Intracranial Pressure. New York, Springer-Verlag, 1993, vol 8, pp 544-548. [Context Link]

22. Miller JD, Smith RR, Holaday HR: Carbon dioxide reactivity in the evaluation of cerebral ischemia. Neurosurgery 30:518-521, 1992. Ovid Full Text 360 Link| Bibliographic Links| [Context Link]

23. Olesen J: Cerebral blood flow methods for measurement regulation, effects of drugs and changes in disease: Chapter V-Oxygen and glucose. Acta Neurol Scand Suppl 50:31-37, 1974. 360 Link| [Context Link]

24. Robertson CS, Narayan RK, Gokaslan AL, Pahwa R, Grossman RG, Caram P Jr, Allen E: Cerebral arteriovenous oxygen difference as an estimate of cerebral blood flow in comatose patients. J Neurosurg 70:222-230, 1989. 360 Link| Bibliographic Links | [Context Link]

25. Rosner MJ, Rosner SD: Cerebral perfusion pressure management of head injury, in Avezaat CJJ, Van Eijndhoven JHM, Maas AIR, Tans JTJ (eds): Intracranial Pressure. New York, Springer-Verlag, 1993, vol 8, pp 540-543. [Context Link]

26. Schröder MLJF: Early ischemia after severe head injury in humans: Evaluation with cerebral blood flow, cerebral blood volume, computed tomography and histology. Amsterdam, the Netherlands, Vrije Universiteit, 1994 (dissertation). [Context Link]

27. Sheinberg MA, Kanter MJ, Robertson CS, Contant CF, Narayan RK, Grossman RG Continuous monitoring of jugular venous oxygen saturation in head-injured patients. J Neurosurg 76:212-217, 1992. 360 Link | Bibliographic Links | [Context Link]

28. Unterberg AW, Andersen BJ, Clarke GD, Marmarou A: Cerebral energy metabolism following fluid-percussion brain injury in cats.J Neurosurg 68:594-600, 1988. 360 Link| Bibliographic Links | [Context Link]

29. van Santbrink $\mathrm{H}$, Maas AIR, Avezaat CJJ: $\mathrm{PbrO}_{2}$ measurements in patients with a severe head injury, in Nagai $\mathrm{H}$, Kamiya K, Ishii S (eds): Intracranial Pressure. New York, Springer-Verlag, 1994, vol 9, pp 582-584. [Context Link]

30. van Santbrink H, Maas AIR, Avezaat CJJ: Serial transcranial Doppler measurements in patients with severe head injury: The early posttraumatic period, in Nagai H, Kamiya K, Ishii S (eds):Intracranial Pressure. New York, Springer-Verlag, 1994, vol 9, pp 585-586. [Context Link]

Back to Top

\section{COMMENTS}

The authors have conducted a thorough evaluation of continuous monitoring of local brain tissue oxygen tension in 22 severely head-injured patients using a Clarktype electrode. The patients were managed by modern intensive methods, thus providing a wealth of physiological monitoring data with which information from the system under evaluation could be compared. The authors have also used tests of reactivity to changes in arterial partial pressure of oxygen and carbon dioxide. Both the continuously recorded data and the results of the reactivity tests have proved valuable in different ways, and the method looks to provide a significant addition to the current armamentarium for patient monitoring in neurointensive care. 
The authors make a useful point about using the system to make a retrospective assessment of the time of brain death in patients, subsequently fulfilling the usual clinical criteria of this state. Such information could be of considerable value in reconstructing the fatal cycle of events in a severely headinjured patient that led to the final adverse outcome.

\section{J. Douglas Miller}

Edinburgh, Scotland

The present report from van Santbrink et al. is the first detailed report of brain tissue oxygen concentration measured using a polarographic microcatheter in headinjured patients. As such, it has both intriguing observations and a host of tantalizing inferences. Although this report is limited to little more than 20 patients, the authors have provided fairly compelling information to indicate that useful information can be obtained from only one brain region. It has been our prejudice that the heterogeneity of partial pressure of brain tissue oxygen would present a significant limitation from a single measure, or perhaps even two, but the authors have provided at least some evidence that this concern might be overdrawn and that we can learn much under the dynamic conditions of head injury from a single recording site in the brain. We found particularly interesting the cycling in partial pressure of brain tissue oxygen, which the authors have shown in Figure 3. Similar cycling has been reported in brain end arterioles and capillaries, and the observation here leads us to speculate that such vascular cycling might be in response to tissue needs for oxygen.

The authors' conclusion that their observations of changes in early partial pressure of brain tissue oxygen accurately reflect failing energy metabolism after head injury seems to be correct. This article, therefore, serves as the basis for future investigations of the metabolism of brain injury and, as such, is a significant and important contribution upon which new work will be built.

Lawrence F. Marshall

Charles J. Wrobel

San Diego, California

Key words: Brain metabolism; Cerebral ischemia; Head injury; Oxygen metabolism

IMAGE GALLERY

Select All

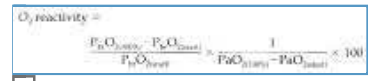

$\square$ Equation 1A

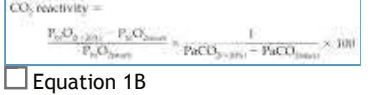

$\square$ Equation 1B

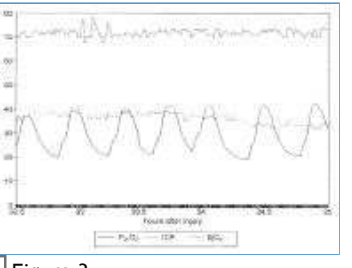

Export Selected to PowerPoint

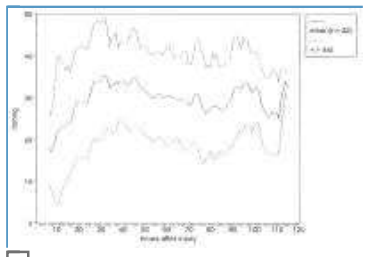

$\square$ Figure 1

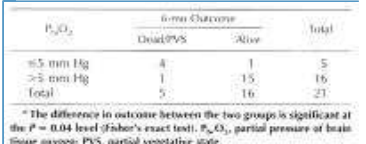

$\square$ Table 1 
Ovid: Continuous Monitoring of Partial Pressure of Brain Tissue Oxygen in Patients wi... Page 12 of 12

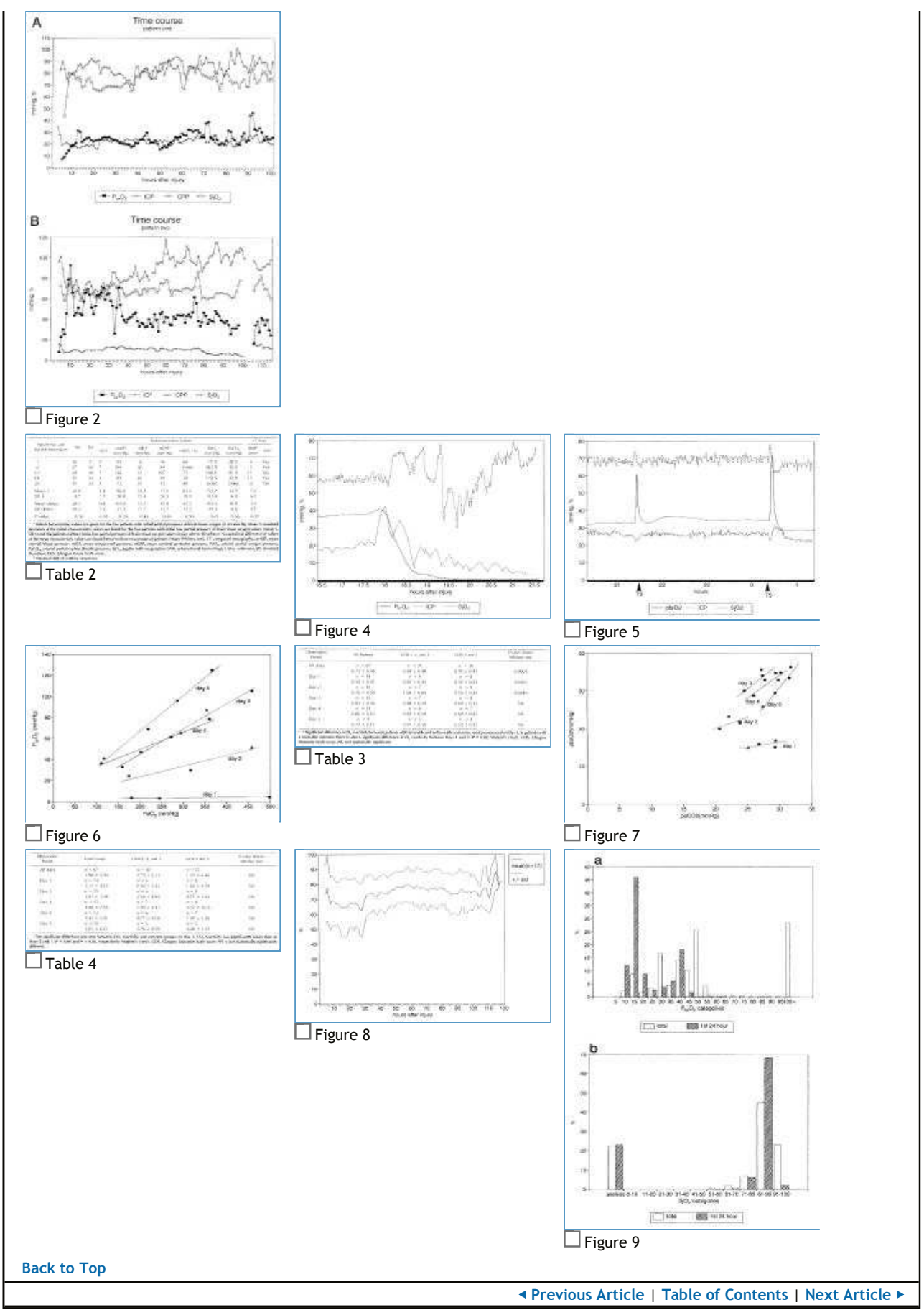

(c) 2015 Ovid Technologies, Inc. All rights reserved. OVidSP_UI03.15.01.102, SourcelD 66680

About Us $\mid$ Contact Us $\mid$ Terms of Use 